\title{
Jenerik Tasarımında Maurice Binder'ın Yeri ve 007 James Bond Film Jenerikleri
}

Arş. Gör. Irem Bilgi

\section{Özet}

Jenerik tasarımı, sinema sektöründe ileri düzeyde bir öneme sahip olan, tanımlı bir alan olarak görülmektedir. Film jenerikleri, izleyiciye film başlamadan önce filmin türü, konusu hakkında ipuçları sunmakta ve film hakkında merakının uyanmasını sağlamaktadır. Bu makalede, jenerik tasarımcısı Maurice Binder 'in Dr. No'dan (1962) başlayarak Licence to Kill (1989) filmine kadar yapmış olduğu "007 James Bond" filmlerinin jenerik tasarımları ele alınmış, jeneriklerde kullanılan tekniklerle kurulan ortak tasarım dili anlayıșı tespit edilmis ve Binder'in grafik tasarım tarihine kattı̆̆ı yenilikçi anlayıș incelenmiștir. Özellikle tüm 007 James Bond filmlerinin açılışında kullanılan Gun Barrel (Silah Namlusu) görüntüsü ve Binder' in jenerik tasarımındaki dehası, döneminin teknolojisine göre dikkate değer buluşlar elde etmiştir.

Anahtar Sözcükler: Jenerik Tasarımı, Maurice Binder, James Bond, Grafik Tasarım, Hareketli Grafik

THE PLACE OF MAURICE BINDER ON GENERIC DESIGN AND 007 JAMES BOND MOVIE GENERICS

\section{Abstract}

Title design is considered as a defined area with advanced level of importance in movie sector. Movie titles offer viewers some tips about the type of the movie, its subject before the beginning and arouse curiousity about the movie. On this article, title designs of "007 James Bond" movies of title designer Maurice Binder starting from Dr. No (1962) till Licence to Kill (1989) movie are addressed. Especially the Gun Barrel image used for the opening parts of all 007 James Bond movies and the prodigy of Binder in title design obtained considerable inventions according to the technology of the era. A common design language understanding established with the techniques used in generics is found and the innovative understanding provided by Binder to graphic design history is examined.

Keywords: Title Design, Maurice Binder, James Bond, Graphic Design, Motion Graphic 


\section{Sinemada Jenerik Tasarımının Önemi}

Jenerik tasarımı, bir film ya da televizyon programının başında seyirciyi izleyeceği ürüne hazırlamak ve bilgi vermek amacıyla oluşturulmuş, görüntü ve ses dizisidir. Seyirci, izlediği ürün hakkında bulmak istediği zorunlu bilgileri jenerikten almaktadır. Bu zorunlu bilgiler, programın ya da filmin oyuncuları, yönetmeni, yapım şirketi gibi teknik kadrosunu içerebilmektedir. Bu detayların dışında jeneriğin, izleyiciye film hakkında türü, konusu, içeriği gibi bilgileri doğru vermek durumunda olduğu düşünülmektedir Bu doğrultuda hazırlanan jenerik, asıl amacına ulaşmaktadır.

Jenerik, hareketli grafiklerden oluşan güçlü bir ifadedir. Onlar filmin başlangıcıdır. İzleyiciyi gerek TV Programı, gerek film, gerekse animasyona hazırlar (Braha ve Byrne, 2011: 1). Başarılı ve etkin bir jenerik tasarımının, hem olması gereken zorunlu bilgileri izleyiciye aktarması hem de film hakkında ipuçları vermesi gerektiği düşünülmektedir. Bu çözümleme de, ancak jenerikte kullanılan görsel ve işitsel elemanların seyircinin algısını başarılı bir biç̧imde yönlendirmekle mümkündür. Bu elemanlar;

- tipografi,

- müzik,

- kamera açıları

- renk ve ışık

gibi, film ya da programın görsel kurgusuna uygun veriler olarak görülmektedir. Bu elemanların doğru kullanımı sayesinde jenerik, izleyiciye gerçek bir hazırlık sunmaktadır. Örneğin titrek kamera hareketleri, sert müzik, keskin bir tipografi ve koyu renklerden oluşan bir jeneriğin, izleyiciyi "korku filmi"ne hazırladığı düşünülebilir. 007 James Bond filmlerinin de aksiyon ve macera konulu filmler olduğu göz önüne alındığında Maurice Binder'in bu duyguyu izleyiciye verdiği görülebilmektedir.

\section{Jenerik Tasarımında Gelişen Yeni Tasarım Anlayışı}

Sinema tarihinde ilk yıllara baktığımızda jenerik tasarımlarının sadece filmin adı, yönetmen, oyuncular, film stüdyosu gibi bilgilerin bulunduğu "title card" (başlık kartları)'ndan ibaret olduğu görebilmektedir. Başlık kartları o yıllarda seyirciye sadece filmin türü hakkında ipucu vermekteydi. Oysa günümüzde jenerik; filmin türü, konusu, karakterleri açısından en önemli verileri izleyice sunmaktadır. Böylece jenerik olmayan bir film düşünülememekte ve jeneriği, bir sektör olarak ele almak gerekmektedir.
Jenerik tasarımının tanımlı bir alan olarak görülmesi 1950'li yıllarda başlamıştır.

1950'lerde Hollywood stüdyolarının mutlak hakimiyeti kırılmaya başlandığında Otto Preminger, Alfred Hitchcock gibi yönetmenler birbirlerinden ve her yere nüfus eden televizyondan kendilerini farklı kılmak istiyorlardı. Kendilerini markalaştırmanın bir yolu da ayırt edici grafikler kullanmaktı. Carmen Jones (1954) bu görsel farklılaştırma yöntemini kullanan ilk filmlerden biriydi. Filmin akılda kalıcı grafik kimliğini, film jeneriği tasarımının öncülerinden olan Saul Bass yaratmışı (Twemlow, 2008: 90).

Saul Bass'ın dışında jenerik tasarımı alanına farklı yaklaşımlar getiren tasarımcılar arasında Maurice Binder, Pablo Ferro, Kyle Cooper, Deborah Ross gibi isimler yer almaktadır.

Maurice Binder, 007 James Bond filmlerinin jenerik tasarımlarına Dr. No (1962) ile başlayarak License to Kill (1989) ile bitirmiştir. Bu 27 yıl boyunca tam 14 adet Bond filmi jeneriğine imzasını atmıştır. Aynı zamanda kariyeri boyunca Fathom, Billion Dollar Brain, Barbarella, The Grass is Greener'in de bulunduğu bir çok farklı filmin jeneriklerini tasarlamıştır. Maurice Binder, 007 James Bond filmi jeneriklerinde ortak bir görsel dil oluşturmuştur. Bu sayede jeneriklerin ilk sahnesinden itibaren Bond filmi olduğu seyirciye aktarılabilmektedir.

\section{Maurice Binder'in 007 James Bond Film Jeneriklerinde Kullandığı} Ortak Dil ve Görsel Teknikler

\section{1. "Gun Barrel" Tekniği}

1918 New York doğumlu olan tasarımcı Binder, 50'li yıllardan sonra Ingiltere'de çalışmaya başlamıştır. Film endüstrisinde ilk tasarladığı jenerik, Stanley Donen'ın 1958 yapımı "Indiscreet" adlı filmidir. 007 James Bond filmleri, konu ve içerik olarak aksiyon dolu, patlamalar ve silahların olduğu ve erotizm barındıran filmlerdir. Maurice Binder'in 007 James Bond filmlerindeki alameti farikasının; soyut ve erotik kadın silüetlerinin mor, kırmızı, mavi renkli arka planlara yansıması olduğu söylenebilmektedir. Binder'in imzası sayılabilecek bir bask ka bulușu da; ilk olarak Dr. No filminde kullandığı, jenerikten önce, Bond filmleri için bir klasik haline dönüşmüş olan ve Gun Barrel tekniği adıyla bilinen "silah namlusu" görüntüsüdür (Krasner, 2008: 19) (Görsel 1). Bu "kült" haline gelmiş olan görüntü, izleyicinin silah namlusunun içinden bakmasıyla başlar, daha sonra ortaya çıkan Bond karakterini takip eder. Sonraki sahnede ise Bond karakteri namluya ateş eder ve ekranın üstünden kan görüntüsü akmaya başlar. 
Binder bu sahnede 38 mm'lik bir gerçek tabanca namlusunun içinden çekim yapmıştır. Bond karakteri her değiştiğinde Binder, namludaki Şean Connery, Roger Moore ya da Pierce Brosnan ile yeni bir çekim gerçekleştirmiştir.

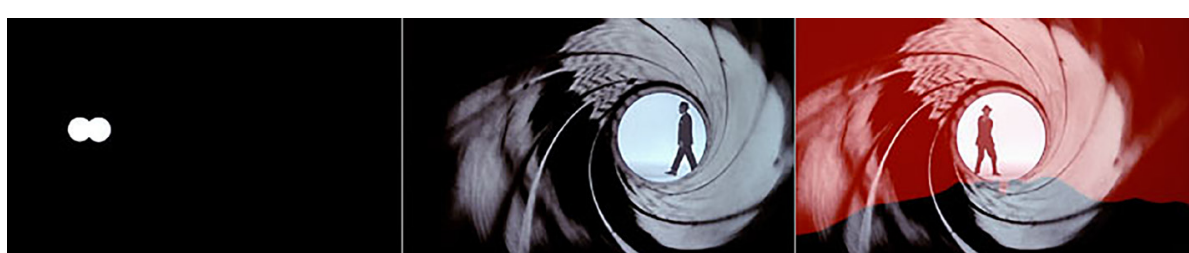

Görsel I. Maurice Binder Dr No filmi, Gun Barrel silah namlusu sahnesi, 1962

Binder, 1983 yılında Starlog dergisine verdiği bir röportajda, silah namlusu sahnesini elde ederken yaşadığı zorlukları şöyle aktarmıştır: “...Kamerayı bir türlü odaklayamıyordum. Ön tarafı netlediğimde arka, arka tarafı netlediğimde ön taraf odaktan çıkıyordu". Binder en sonunda Pinhole fotoğraf kamerası mekanizmasından esinlenerek doğru netlemeyi gerçekleştirmiştir (Mc Gregor, 1983).

Gun Barrel sahnesi Binder'in başlattığı bir gelenek haline gelmiştir Tüm James Bond film serilerinin başlangıcındaki 15 sn görülmektedir ve ardından serideki her filmin jeneriği başlamaktadır. Binder'in jenerik tasarım tarihindeki tek buluşu Gun Barrel tekniği ile sınırlı kalmamıştır. Binder, kinetik tipografiyi başarılı bir biçimde kullanan tasarımcılardan biri olmakla birlikte, yansıtma, görüntü üzerine maskeleme tekniklerini kullanmıştır.

\section{Kadın Silüetleri}

Görsel tasarımda nesneleri grafik haline getirmenin pek çok yolu vardır Işığın nesnenin arkasında kullanımı ile oluşan silüeti, tasarım öğesi olarak işlenebilmektedir. Blank ve Garcia (1986:61) grafiklerle birleştirilmiş silüetlerin tam bir grafik kontrast aralığı sağladığını belirtmiştir.

007 James Bond filmlerinin her birinde ortak özellik olarak "Bond Kızları" mevcuttur. Filmlerde içerik bakımından aksiyon sahnelerinin yanı sıra Bond Kızları'nın bulunduğu erotik sahneler yer almaktadır. Binder, 007 James Bond filmleri serisinin jenerik tasarımında bu kadın figürlerini kullanmıştır. Tasarımcıya ait 007 James Bond filmi jeneriği 1962 yılında Dr. No (Görsel 2)'den itibaren bu figürler görülmektedir. Resim 3'de dans eden çıplak kadın silüetleri, Binder'in sıklıkla tercih ettiği kırmızı, mor ve mavi renkler kullanılarak yansıtılmıştır.

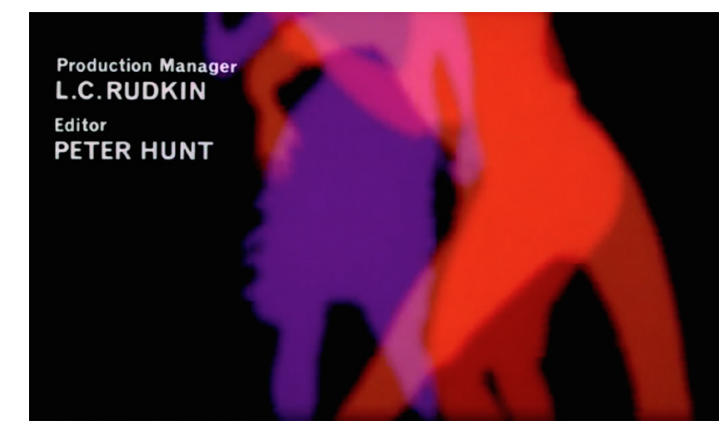

Görsel 2. Dr. No, 1962
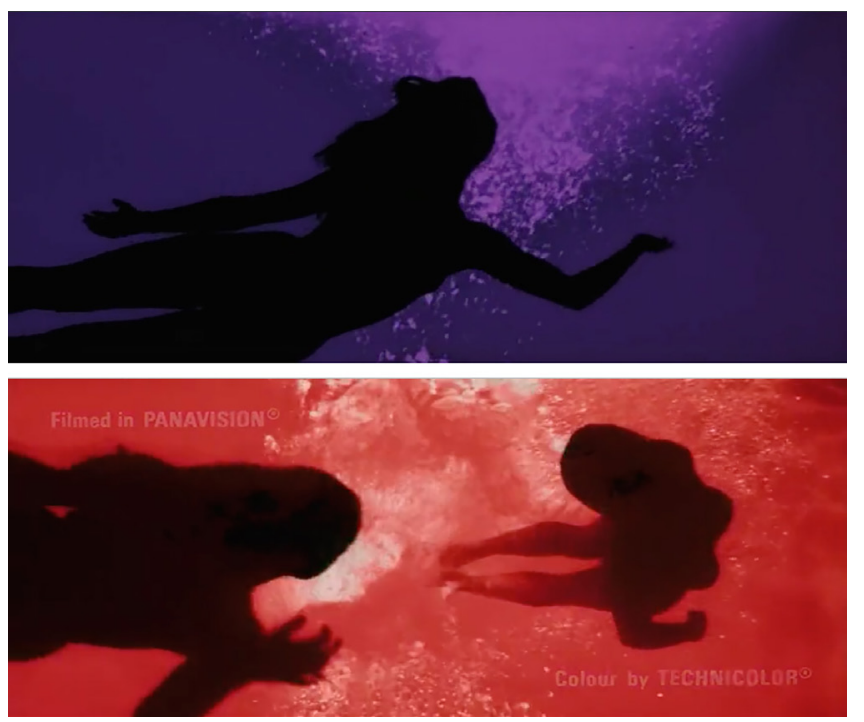

Görsel 3. Thunderball, 1965

\section{Yansitma}

Maurice Binder, Bond serisinin jeneriklerine 1963 yılı yapımı From Russia with Love ve 1964 yılı yapımı Goldfinger fimleriyle ara vermiştir. Bu sırada Robert Brownjohn, 1963 yılında 007 James Bond serisinin From Russia with Love filminin jeneriğinde dans eden kadın oyuncunun vücudunu bir ekran gibi göstermiş ve projektör ile tipografiyi oyuncunun vücuduna yansıtmıştır (Görsel 4). Oyuncu, dans ederken çıplak vücutta zorunlu bilgilerin hem okunması hem de hareket etmesi gerekmektedir. Inceer (2007: 36) kadın oyuncunun yazıların net algılanması için dans ederken çok dikkatli hareket etmekte olduğunu belirtmiştir. Aynı zamanda Brownjohn ve ekibinin bu 
tasarımda yüksek güçlü bir projektör, renkli camlar ve filtreler kullandığını belirtmektedir

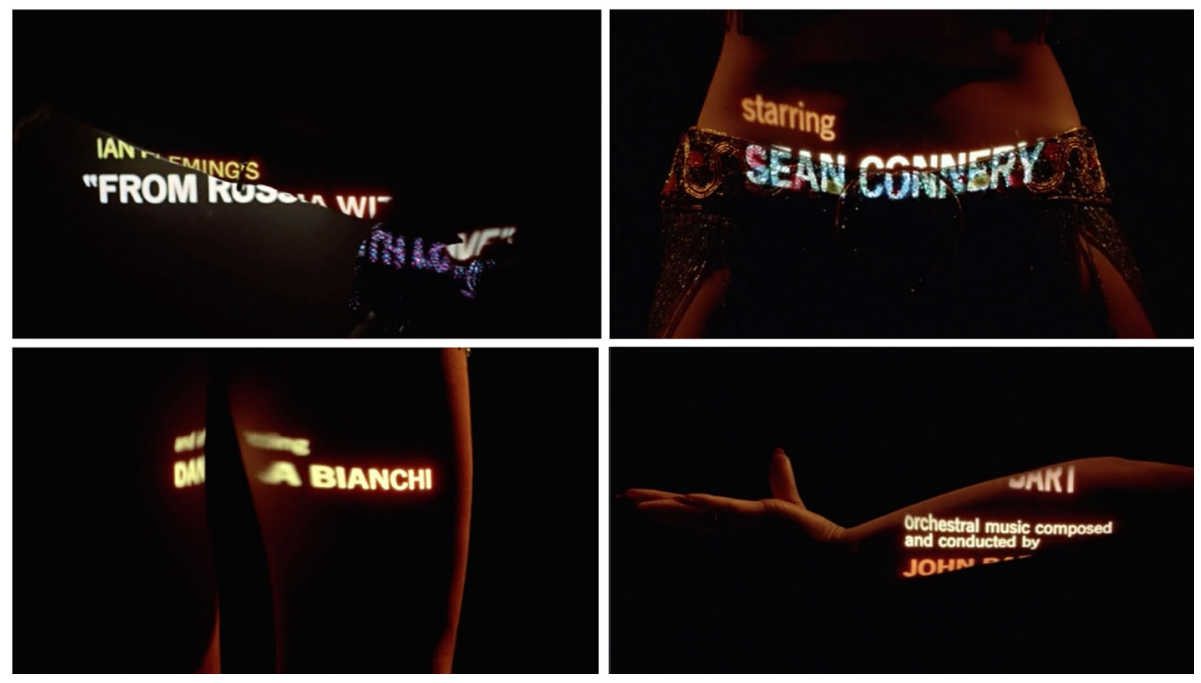

Görsel 4. From Russia with Love, 1963

Brownjohn'un 1964 yılında Goldfinger film jeneriği tasarımında da ayn yansıtma tekniğini kullanmasının ardından 1983 yılında Binder, Octopussy filminde Brownjohn'a teknik bir gönderme yapmıștır. Binder bu filmin jeneriğinde 19 yılın ilerleyen teknolojisini kullanarak kadın vücudu üzerine lazer yansıtarak bir hikaye belirlemiştir (Görsel 5).

Octopussy filminin jeneriğinin genelinde kamera açıları close up (yakın plan) olarak kullanılmıştır. Oyuncunun vücudu bir arkaplan olarak kullanıldığı için adeta bir zemin işlevi görmektedir.
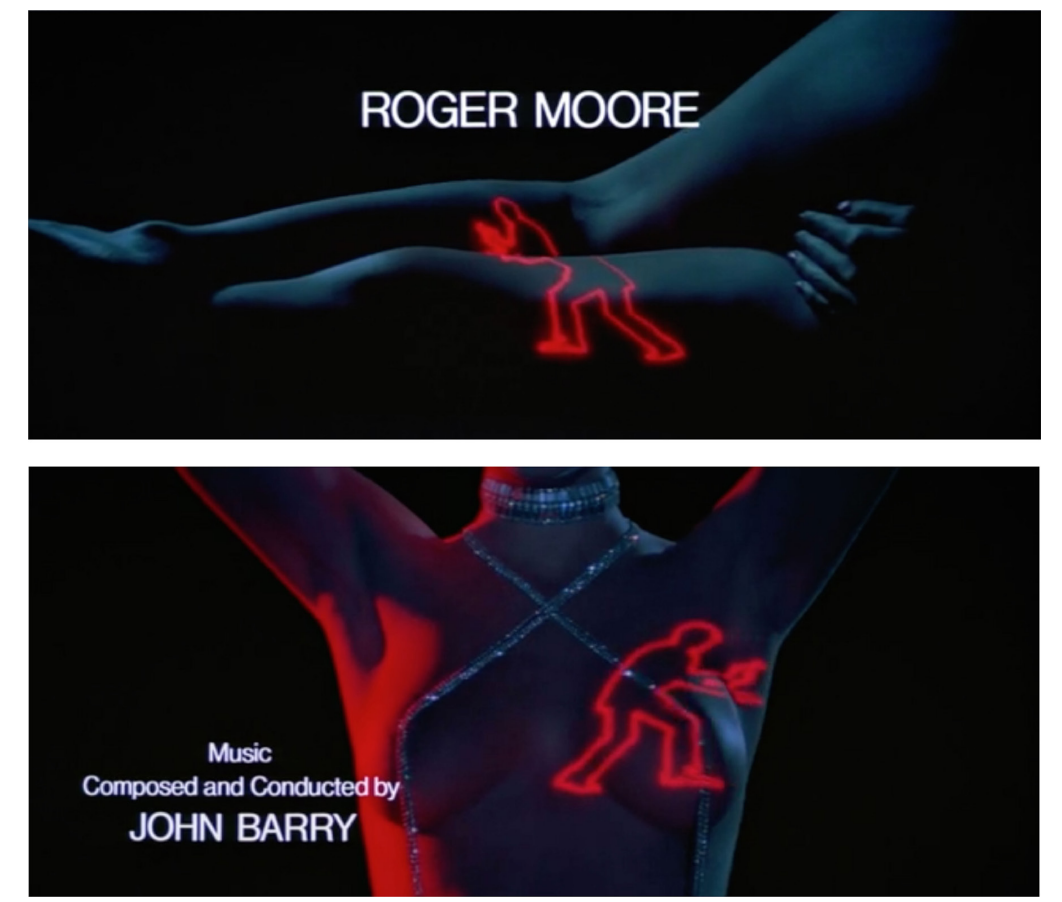

Görsel 4. From Russia with Love, 1963

Binder'in 007 James Bond filmleri serisinde kadın vücudunu zemin olarak kullandığı başka örnekler de bulunmaktadır (Resim 6) Tasarımcı, "The Living Daylights" filminin jeneriğinde lazerle yansıtma tekniği yerine projeksiyon kullanmıştır.

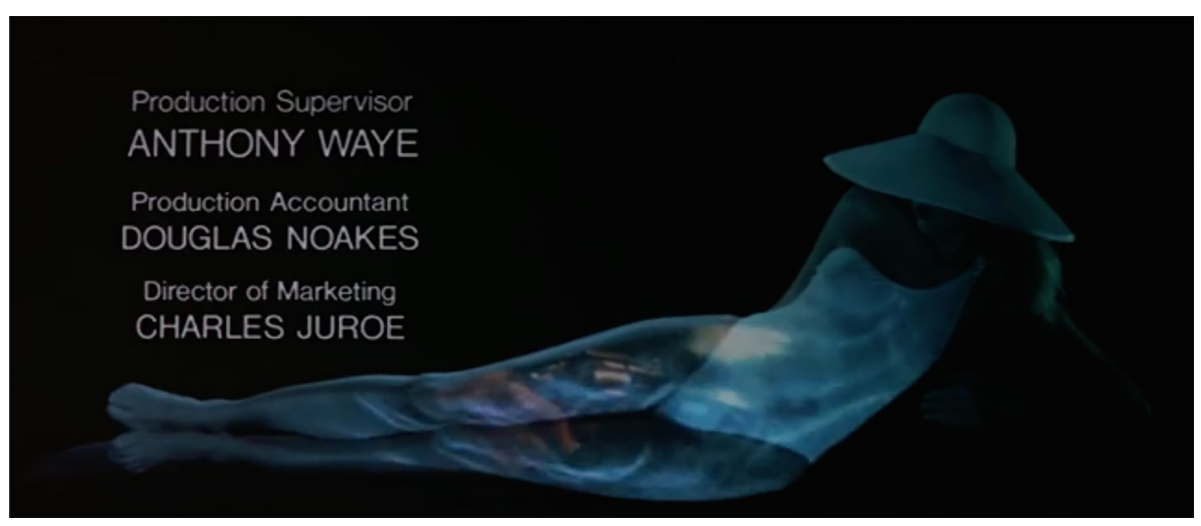

Görsel 6. The Living Daylights, 1987 
1981 yapımı For Your Eyes Only, Binder'in jenerik tasarımında bir çok tekniği birleştirdiği bir film olarak sayılabilmektedir. Jeneriğin giriş kısmında ana karakter olan James Bond görüntüsü, kadın figürüne yansıtılarak kullanılmıştır (Görsel 7).

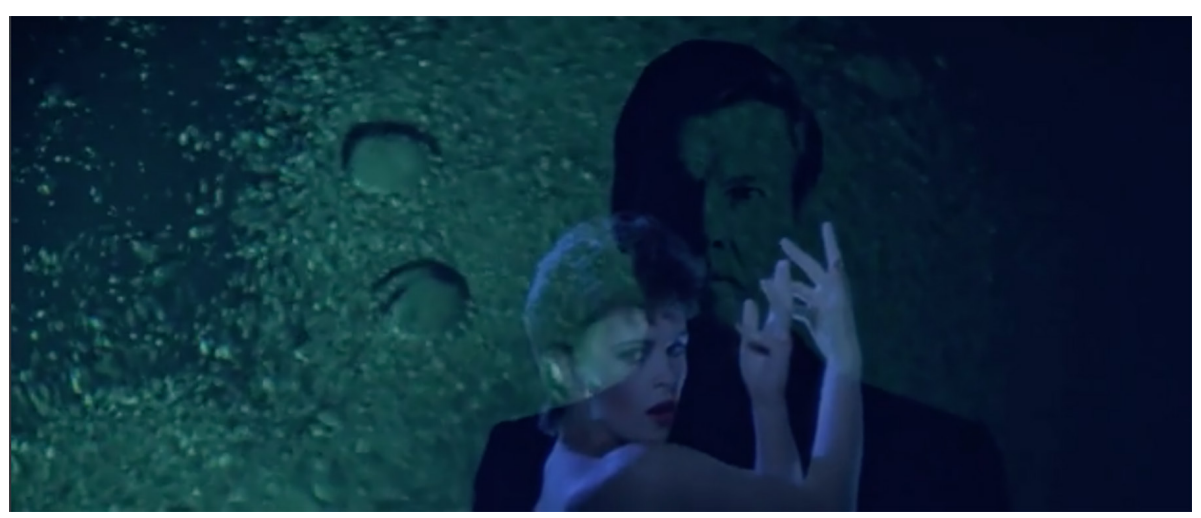

Görsel 7. For Your Eyes Only, 198I

Robert Brownjohn, 1963 yılında 007 James Bond film jeneriklerinde kadın figürlerine projeksiyonla görüntü yansıtma tekniğini uygulamış olsa da Maurice Binder ilerleyen yıllarda bu tekniği kendi yorumu ve profesyonelliği ile bir çok filmde uygulamıştır.

\section{Tipografi}

Jenerik tasarımında tipografi, film hakkında izleyiciye sunulması gereken ipuçlarını veren başlıca tasarım elemanlarından biri olarak görülmektedir. $\mathrm{Bu}$ bağlamda film jeneriklerinin filmin duygusunu yansıtabilmesi de tipografinin hareketiyle yönlenmektedir. Hillner (2009: 100), film jeneriklerinin hareketli grafiklerin ve geçişli tipografinin kökeni olarak görülmekte olduğunu belirtmiştir

Binder, 007 James Bond filmlerinin jenerik tasarımlarında genel olarak serifsiz, majiskül ve beyaz renkte modern fontlar kullanmıstır. Tasarımcının font ile vermek istediği bu ortak tasarım dili anlayışı 007 James Bond filmleri için geleneksel sayılmaktadır. 1963 yılı yapımı Thunderball (Görsel 8) filminin jeneriğinde Binder, filmin konusuyla paralellik sağlayarak su altı temasını her grafiksel öğede kullanmıştır. Su altındaki harekete göre yön bulan ve bozulmalara uğrayan tipografik tarz daha sonra Live and Let Die (1973) film jeneriğinde kullanılmıştır (Görsel 9).
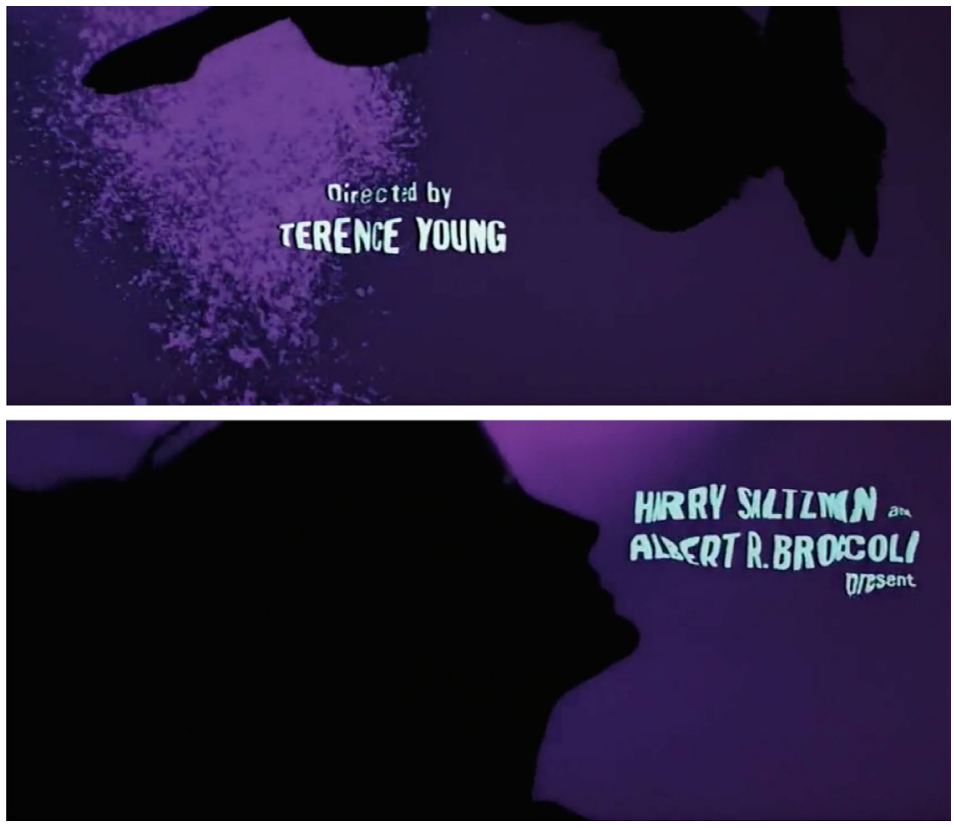

Görsel 8. Thunderball, 1965

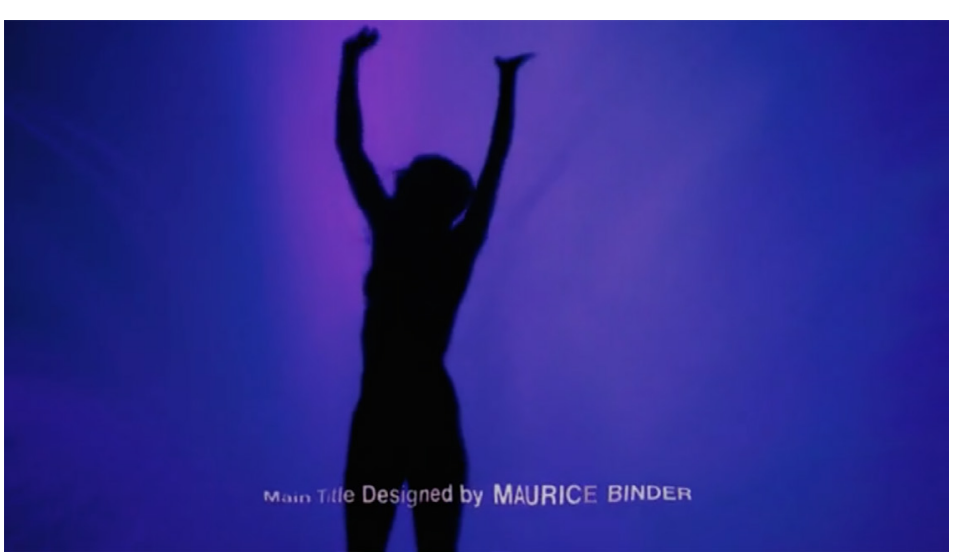

Görsel 9. Live and Let Die, 1973

\section{Görüntü Üzerine Maskeleme}

Maurice Binder'in 007 James Bond film jeneriklerinin tasarımlarında kullandığı maskeleme tekniğinin jenerik tasarım tarihine büyük katkısı olduğu söylenebilir. Binder, önceden uyguladığı görüntüleri silüet olarak kullanma tekniğini bu kez negatife çevirerek hareketli görüntüleri negatif 
silüetlerin içine yerleştirmiştir. Licence To Kill (1989) (Görsel 10), On Her Majesty Service (1969) (Görsel 11), You Only Live Twice (1967) (Görsel 12), filmlerinin jeneriklerinde bu yöntem etkin olarak görülebilmektedir.

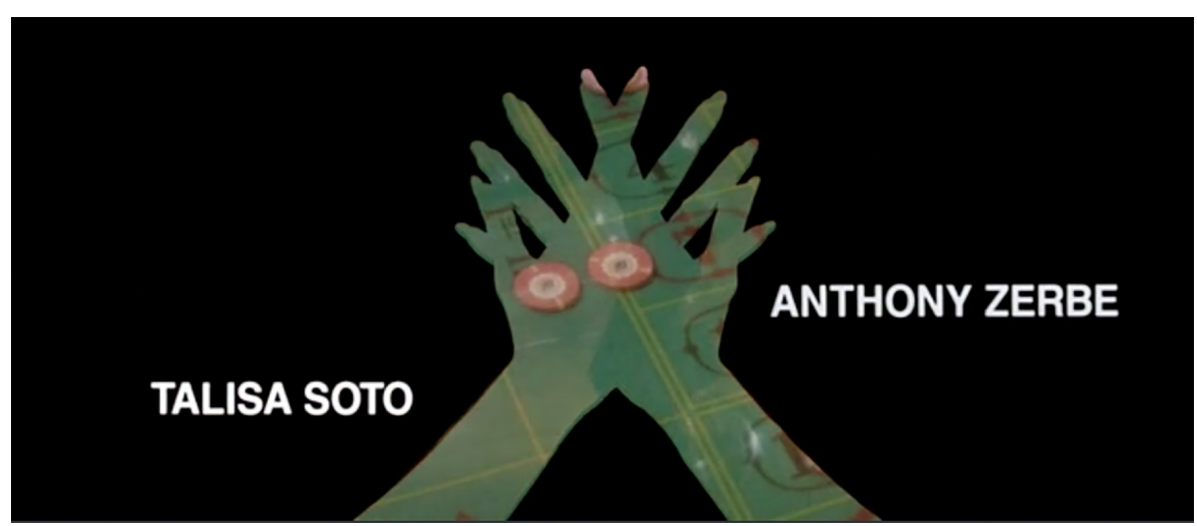

Görsel IO. Licence to Kill, 1989

Teknik olarak maskeleme, bir imajın belirli kısımlarını gizleyerek bütününü parçalar halinde göstermektir. Örneğin "On Her Majesty's Secret Service" film jeneriğinin Görsel 11 'de görülen ekran alıntısındaki erkek görselinin olduğu fotoğraf, kum saati imajıyla maskelenmiş ve kum saati boyutlarının dışında kalan tarafı gizlenmiştir. Maskeleme, geçmişteki manuel tasarımlardan günümüzde kullanılan bilgisayar programlarına kadar her zaman geçerliliğini korumuş bir yöntem olmasına karşılık Binder tarafından jenerik tasarımına farklı bir tarz getirmiştir.

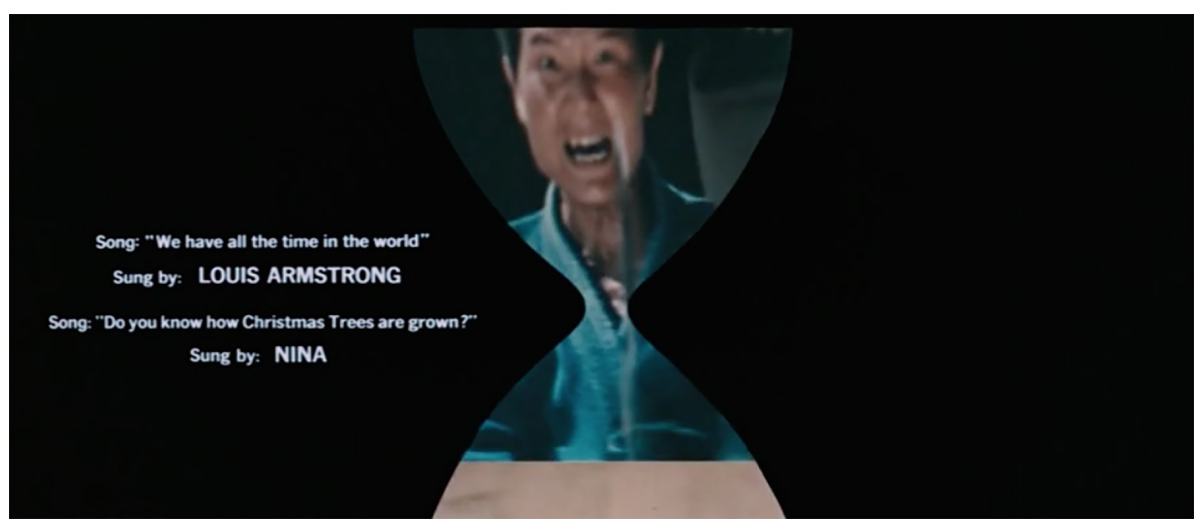

Görsel IO. Licence to Kill, 1989

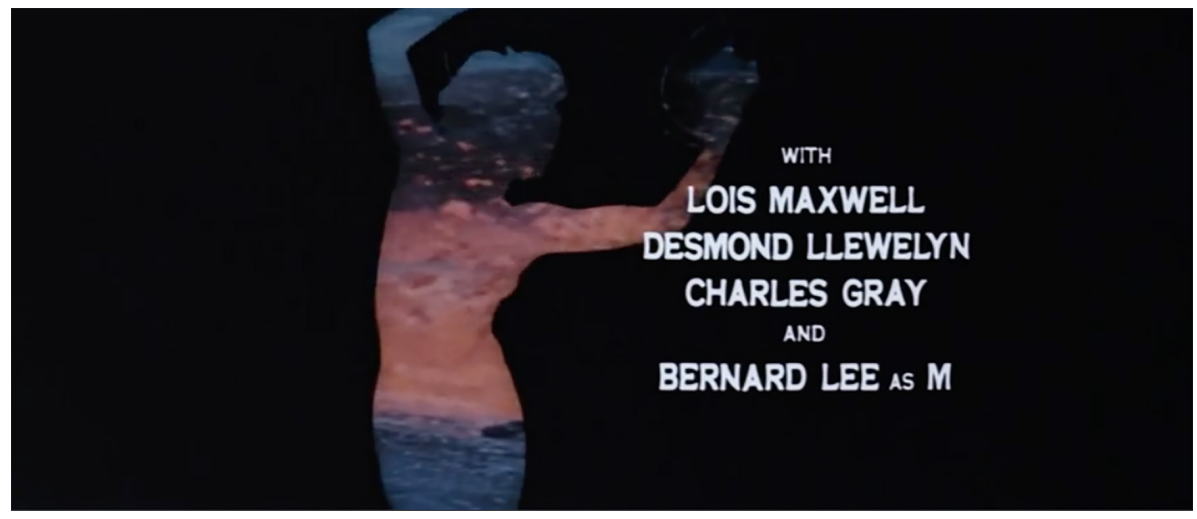

Görsel 12. You Only Live Twice, 1967

Sonuç

Sinema ve grafik tasarımın ortak alanı olarak görülen jenerik tasarımı hareketli grafik alanına katkı sağlayan önemli bir çalışma alanı olarak sayılmaktadır. Grafik tasarım tarihinde başlıca sayılabilecek jenerik tasarımcısı olan Maurice Binder, döneminin elverdiği teknolojiyle 007 James Bond filmlerinin jeneriklerini tasarlayarak günümüzde örnek teşkil eden eserler üretmiştir.

Maurice Binder'in tasarımlarını yaptığı 007 James Bond filmleri jenerikleri, 1962 yılından 1989 yılına kadar gelişen teknoloji ve yeni teknikler sayesinde farklııklar göstermesine karşılık filmin tüm serileri için bir bütün halinde görünmektedir. Örneğin; önceki bölümlerde konusu geçen Gun Barrel tekniği bu teknolojik gelişmeler ile zaman içinde evrilmiş ve yeni teknikler uygulanarak modernize edilmiştir. 1980li yıllarda bilgisayar temelli tasarıma geçilmesi, Bond serisi jeneriklerinde farklı keşiflere yol açmıştır.

Aksiyon türü sinema dahilinde olan 007 James Bond filmlerinde, araştırmada da bahsi geçmekte olan "Bond Kızları", Binder tarafından jeneriklerde dans eden silüetler olarak kullanılmıştır. Binder, tasarımlarında sembolleştirdiği bu silüetleri genelde mor, lacivert, kırmızı ve mavi arkaplanlara yerleştirmiştir. Bu silüetleri görmemizin nedeni James Bond'un çapkın karakterinin filmlerde ön planda olmasındır. Jenerik tasarımı açısından bakıldığında silüetler aracılığyla film hakkında bu ipucu elde edilebilmektedir. 007 James Bond film jeneriklerindeki diğer ipuçları (silahlar, patlama sahneleri, kötü alışkanlıklara dair sahneler) izleyiciyi karşılaşacağı film türüne hazırlamakta ve film hakkında merak uyandırmaktadır. Maurice Binder'in sağladığı tüm bu ipuçları, elde ettiği yeni tasarım teknikleriyle grafik tasarım tarihine katkı sağlamıştır. 
Günümüzde pek çok sinema filmi serisinin jenerikleri ortak bir tasarım anlayışına sahip olarak görünmektedir. Ancak Maurice Binder'in, uzun yıllar çalıştığı 007 James Bond film serisinde kendi dönemi için sayılabilecek yenilikçi ve çağdaş bakış açısı bugün de geçerli kılınmaktadır.

\section{Kaynakça}

Blank, B. ve Garcia, M. (1986). Professional Video Graphic Design the Art And Technology. New York: Prentice Hall Press.

Braha, B. ve Byrne B. (20II). Creative Motion, Graphic Titling for Film, Video, and the Web. China: Elsevier.

Hillner, M. (2009). Basics Typography $0 I$ - Virtual Typography. Singapore: AVA Publishing SA.

Inceer, M. (2007). An Analysis of the Opening Credit Sequence in Film. Doktora tezi. University of Pennsylvania, Pensilvanya.

Krasner, J. (2008). Applied History and Aesthetics. China: Elsevier.

Mc Gregor, D. (1983). Maurice Binder: Sighting Down a Gun Barrel at 007. Starlog Dergisi, Eylül (2I)

Twemlow, A. (2008). Grafik Tasarım Ne İçindir?. İstanbul: Yem Yayın.

\section{Görsel Kaynakları}

Görsel I: Dr. No filmi açllş̧ jeneriği, 1962, Video http://www.artofthetitle.com/title/dr-no/ adresinden I Mart 2018'de alınmıştır.

Görsel 2: Dr. No filmi açllş̧ jeneriği, 1962, Video http://www.artofthetitle.com/title/dr-no / adresinden I Mart 2018'de alınmıştır.

Görsel 3: Thunderball filmi açılış jeneriği, 1965, Video http://www.artofthetitle.com/title/ thunderball// adresinden I Mart 2018'de alınmıştır.

Görsel 4: From Russia with Love filmi filmi açılış jeneriği, 1963, Video http://www. artofthetitle.com/title/from-russia-with-love/ adresinden I Mart 2018'de alınmıştır.

Görsel 5: Octopussy filmi açıllş jeneriği, 1983, Video http://www.artofthetitle.com/title/ octopussy/ adresinden I Mart 2018'de alınmıştır.

Görsel 6: The Living Daylights filmi açllş jeneriği, 1987, Video http://www.artofthetitle. com/title/the-living-daylights/ adresinden I Mart 2018'de alınmıştır.

Görsel 7: For Your Eyes Only filmi açılış jeneriği, 198I, Video http://www. artofthetitle.com/ title/for-your-eyes-only/ adresinden I Mart 20I8'de alınmıştır.

Görsel 8: Thunderball filmi açılış jeneriği, 1965, Video http://www.artofthetitle.com/title/ 
thunderball// adresinden I Mart 2018'de alınmıştır.

Görsel 9: Live and Let Die filmi açılış jeneriği, 1973, Video http://www.artofthetitle.com/ title/live-and-let-die adresinden I Mart 20I8'de alınmıştır.

Görsel 10: Licence to Kill filmi açılış jeneriği, 1989, Video http://www.artofthetitle.com/ title/licence-to-kill/ adresinden I Mart 20/8'de alınmıştır.

Görsel II: On Her Majesty 's Secret Service filmi açılış jeneriği, 1969, Video http:/l www.artofthetitle.com/title/on-her-majestys-secret-service/ adresinden I Mart 2018'de alınmıştır.

Görsel I2: You Only Live Twice filmi açılış jeneriği, 1967, Video http://www.artofthetitle. com/title/you-only-live-twice/ adresinden I Mart 2018'de alınmıştır. 